\title{
Projeto brincar e contar: a terapia ocupacional na atenção básica em saúde ${ }^{1}$
}

\author{
Débora Barbosa e Alcântaraa ${ }^{a}$, Cristiane Miryam Drumond de Brito ${ }^{b}$ \\ ${ }^{a}$ Especialista em Saúde da Família e Comunidade, Terapeuta Ocupacional, Núcleo de Apoio a Saúde da Família - NASF, \\ Associação Saúde da Família, Prefeitura de São Paulo, São Paulo, SP, Brasil \\ ${ }^{b}$ Professora Doutora, Departamento de Terapia Ocupacional, Universidade Federal de Minas Gerais - UFMG, \\ Belo Horizonte, MG, Brasil
}

\begin{abstract}
Resumo: Este artigo relata uma experiência de um grupo de contação de histórias e brincar ocorrida nas dependências de uma Unidade Saúde da Família do município de São Carlos, SP. Esse grupo foi constituído a partir da avaliação da terapeuta ocupacional no contexto da atenção básica à saúde de forma ampliada que considerou a vida cotidiana dos envolvidos: as crianças, uma usuária do serviço e a equipe de saúde. Através do olhar da terapia ocupacional para as problemáticas do território foram propostas intervenções que articulavam o cuidado individual, o cuidado coletivo e a corresponsabilização da comunidade e da equipe na busca da ressignificação do cotidiano desses atores. Trata-se de um exemplo concreto de mudança de paradigma do modelo de saúde existente para os preceitos da Estratégia Saúde da Família com o envolvimento de usuários e profissionais de várias áreas. A terapeuta ocupacional identificou diferentes demandas do território: a necessidade de transformação do cotidiano e da rotina de uma usuária, a necessidade de espaços de lazer e brincadeiras para as crianças no território e o desejo da equipe de construir esse espaço através de uma brinquedoteca. A possível junção das realidades cotidianas da usuária, das crianças e da equipe constituiu um projeto de intervenção baseado na visão da clínica ampliada. $\mathrm{O}$ "Brincar e Contar" foi capaz de transformar na prática o modelo de atenção à saúde.
\end{abstract}

Palavras-chave: Terapia Ocupacional, Saúde da Família, Território, Atenção Básica à Saúde, Crianças.

\section{Project 'play and tell': occupational therapy in primary health care}

\begin{abstract}
This paper reports the experience of a "storytelling and playing" group that took place in a Family Health Unit in Sao Carlos, State of Sao Paulo. The group was formed as from the evaluation of the occupational therapist in the context of Primary Health Care, which broadly considers the daily lives of the actors involved: children, one user of the system, and the health team. From the viewpoint of Occupational Therapy, with focus on the problems of the territory, interventions linking the following matters were proposed: individual care, collective care, and co-responsibility of the community and staff in pursuit of the resignificance of the everyday lives of the actors involved. This is a concrete example of paradigm shift from the existing health model to the precepts of the Family Health Strategy, with the involvement of users and professionals from various areas. The occupational therapist identified different demands of the territory: the need for transformation of daily life and routine of a user; the need for children's leisure; and the desire of the health team to build this space through a playroom. The possible combination of the user, children and the team's everyday realities composed an intervention project based on the vision of the clinic expanded. The "playing and storytelling" was able to actually transform the health care model.
\end{abstract}

Keywords: Occupational Therapy, Family Health, Territory, Primary Health Care, Children.

Autor para correspondência: Débora Barbosa e Alcântara, Núcleo de Apoio a Saúde da Família, Rua Wenceslau Ralish, 103, Jd Sertãozinho, CEP 04826-240, São Paulo, SP, Brasil, e-mail: deborabalcantara@gmail.com

Recebido em 27/5/2011; Revisão: 2/12/2011; Aceito em 11/1/2012. 


\section{Introdução}

Este artigo relata uma experiência de um grupo de contação de histórias e brincar ocorrida no território de uma Unidade Saúde da Família, na cidade de São Carlos, SP. Trata-se de um exemplo concreto de mudança de paradigma do modelo de saúde a inserçáo de usuários e de profissionais nos preceitos da Estratégia de Saúde da Família. O relato está contextualizado da seguinte forma: um recorte da história do grupo, reflexōes sobre o brincar, a terapia ocupacional ressignficando o cotidiano das pessoas envolvidas no projeto, tecendo encontros e conclusão.

\subsection{Contando um recorte desta história}

A terapeuta ocupacional e a educadora física residentes do Programa de Residência Multiprofissional em Saúde da Família e Comunidade da Universidade Federal de São Carlos foram solicitadas pela equipe da Unidade de Saúde da Família a realizar uma visita domiciliar na casa de uma mulher cadeirante que queixava do ócio no seu cotidiano. No primeiro encontro, a terapeuta ocupacional iniciou a coleta de dados da história de vida da usuária tendo como referencial o seu cotidiano. Esse referencial considera a subjetividade e os fazeres remanescentes no cotidiano e na rotina. Buscou-se compreender os sentidos do dia a dia da usuária e essa ação possibilitou a descoberta de atividades que lhe davam prazer e motivação, como o gosto por filmes e leitura. A atividade que mais fazia sentido para Joana ${ }^{2}$ acontecia no período noturno. Ela assistia, em média, dois (2) filmes por noite, com o filho de 20 anos. A usuária acordava tarde e, quando era possível, lia durante o dia. O ócio descrito por ela dizia respeito à circulação no ambiente social e às atividades de vida diária.

Paralelamente à coleta de história de vida dessa usuária, a terapeuta ocupacional e a equipe da unidade constataram que as crianças daquela região tinham carência de espaços lúdicos no território. Em eventos coletivos como a comemoraçáo do Dia das Crianças ou a realizaçáo de um bingo adaptado (chamado Bingão da Saúde) ${ }^{3}$ direcionado ao público adulto da comunidade, notou-se um público predominantemente de crianças. Identificou-se que as crianças buscavam a participaçáo no território para além da escola, um espaço de convívio social no lugar onde moram. Diante dessas constataçóes, a equipe de referência da unidade, juntamente com reflexóes trazidas pela Terapia Ocupacional e pela equipe matricial ${ }^{4}$, teve o desejo de criar uma brinquedoteca no território, pois reconheceu a escassez de espaço para as crianças, espaços culturais e de promoção de saúde. Junto à equipe e com vivências prévias da terapeuta ocupacional, que participou de um projeto de uma brinquedoteca aberta à comunidade no período em que era estudante de graduação no município de São Paulo, construiu-se mais concretamente a ideia de criar uma brinquedoteca no território em que se localizava a unidade de saúde da família em São Carlos. Através de estudos sobre o assunto, levantamento de materiais e busca de espaço para montagem da brinquedoteca, foi concluído que náo era possível até aquele momento montar uma, por a unidade não possuir espaço físico suficiente.

Foi com todos esses dados, sobre o cotidiano quase sempre ocioso de Joana, a demanda das crianças por espaços lúdicos e coletivos e o desejo da equipe da unidade de Saúde da Família de construir uma brinquedoteca que a Terapia Ocupacional articulou um projeto de ação no território. As demandas a princípio vistas de forma separada poderiam ganhar potência se trabalhadas em redes de diálogos e comunicação. Desse modo, a terapeuta ocupacional propôs a criação do projeto "Brincar e Contar" e possibilitou iniciar a construção da ideia da brinquedoteca no espaço domiciliar de Joana. A partir do conjunto de demandas identificadas foram pensadas estratégias viáveis para a sua satisfação.

\subsection{Um pouco sobre o porquê brincar}

A terapeuta ocupacional integrante da equipe matricial da unidade de saúde da família auxiliou na construção do perfil do público atendido pelo projeto "Brincar e Contar" e deu respaldo teórico para a qualificação e o suporte técnico de atuação da equipe. A terapeuta ocupacional e seu repertório de atuação trouxeram para a equipe os benefícios que as crianças do território passariam a ter se fosse providenciado um espaço facilitador do brincar. Ela mesma reescreveu e desenvolveu um projeto denominado "Brincando no Território" (GALLETTI et al., 2008) do Centro de Convivência e Cooperativa no bairro Parque Previdência, em São Paulo, quando ainda estudante de graduação - as reflexóes sobre o brincar neste artigo foram retiradas dessa experiência.

O brincar sempre esteve presente no cotidiano infantil, mas, até pouco tempo, pouca importância se dava a esse ato. Atualmente, sua importância é reconhecida e consta na Declaração Universal dos Direitos da Criança (aprovada na Assembléia Geral das Naçóes Unidas em 1959), no artigo 70: “Toda criança terá direito a brincar e a divertir-se, cabendo 
à sociedade e às autoridades públicas garantir a ela o exercício pleno desse direito." (BRASIL, 1990).

O processo de desenvolvimento infantil se dá por meio da interação com o mundo e com as outras pessoas. A atividade de brincar está presente em todo esse processo e é um ato espontâneo que pode ser observado desde poucos meses de vida.

Bundy (2000) definiu brincar como uma sendo a relação dinâmica desenvolvida pela interação da criança com o ambiente, na qual a ação é intrinsecamente motivada, internamente controlada e com suspensão da realidade objetiva. Desta forma, o projeto "Brincar e Contar" se apresenta como um espaço livre para que a criança possa expressar-se como uma forma de estar no mundo, falar de si e desenvolver-se.

O brincar da criança se dá pela imitação de atividades sociais que desempenha a partir do que observa no mundo adulto, o que estimula o seu desenvolvimento cognitivo e social. Quando as crianças brincam juntas, elas estão testando possibilidades de ser, buscando alternativas de solucionar conflitos e ainda compartilhando experiências de vida.

A brincadeira permite que a criança resolva de forma simbólica problemas náo resolvidos do passado e enfrenta, direta ou simbolicamente, questôes do presente [...] (BETTELHEIM, 1998, p. 144).

Winnicott (1975a) mostra em sua obra como a brincadeira está relacionada não só ao desenvolvimento como também à saúde. Diz que a saúde é a capacidade de sofrer e ainda assim ter esperança, o que está implícito na brincadeira, pois há nela espaço para a frustração e a integração. Quando a criança brinca, tem a oportunidade de viver suas frustraçôes e de aprender a lidar com elas. É por meio da brincadeira que as crianças podem entrar em contato com conteúdos internos e elaborar questóes pessoais. Sendo assim, a criança que não brinca não tem um desenvolvimento saudável e adoece mais.

\section{Para Winnicott (1975b, p. 63),}

$\mathrm{O}$ desenvolvimento infantil considera que o ato de brincar é mais que a simples satisfação de desejos. O brincar é o fazer em si, um fazer que requer tempo e espaços próprios; um fazer que se constitui de experiências culturais, que é universal e próprio da saúde, porque facilita o crescimento, conduz aos relacionamentos principais, podendo ser uma forma de comunicação consigo mesmo (a criança) e com os outros.
O brincar, portanto é atividade principal da criança e é necessário para o ensino-aprendizagem, desenvolvimento e a saúde da mesma.

O olhar sobre as crianças como sujeitos articulados a uma compreensão sobre a importância do brincar tem se mostrado uma estratégia fundamental de efetivação de uma concepção de infância com direitos subjetivos e singularidades em seu processo de inserção na cultura (DEBORTOLI; LINHALES; VAGO, 2005). Quando se propôe a inserção do brincar assistido é recomendável que os profissionais ocupem o lugar de facilitadores do brincar. Essa situação possibilita variar o contexto, envolvendo a criança na escolha, na discussão e no planejamento do brincar; e aproveitar experiências da "vida real" e a experiência da criança no mundo real; compreender que nem sempre a brincadeira acontece no faz de conta, ouvir e observar cuidadosamente, buscando respeitar o espaço da criança.

\subsection{O ressignificado dos cotidianos}

A história de vida de Joana indica que depois de uma anemia grave passou a utilizar prioritariamente uma cadeira de rodas para a locomoção, mas ela também consegue deambular, com dificuldades, pois sente fraqueza muscular. Esse seu estado de saúde fez com que ela interrompesse seu trabalho formal remunerado e diminuisse suas atividades domésticas. As atividades domésticas passaram a ser realizadas pelos filhos, também responsáveis pelo sustento da família, condição essa que, consequentemente, interferiu em seu autocuidado, na forma em que lida consigo mesma e com a vida. A autoestima de Joana baixou, ela tornou-se uma pessoa sem desejos, desmotivada da realização de atividades e construção de projetos de vida. Nem mesmo para as atividades recomendadas pelos profissionais de saúde, como exercitar-se e manter os movimentos de membros inferiores, ela encontrava motivação para executar.

Não cabia à Terapia Ocupacional realizar atividades para que Joana ocupasse seu tempo, era necessário reinventar seu cotidiano, construir uma nova rotina, com novos significados.

A Terapia Ocupacional compreende a pessoa entre a objetividade de seu problema e a subjetividade da interpretação de suas necessidades, entre seu modo de perceber a vida e aquele do terapeuta ocupacional, entre a técnica e as dificuldades reais do cotidiano [...] (BARROS; GHIRARDI; LOPES, 2002, p. 95-103).

Joana, com limitaçóes de circulação em seu cotidiano, construiu sua vida de modo a dormir 
durante o dia, para ficar acordada à noite, em atividades noturnas de assistir a filmes com seu filho e, esporadicamente, atividades diurnas de leitura da livros. Durante o dia, com restriçóes físicas e talvez um desejo de não lidar com a crença de que era impotente para realizar atividades, trabalhar ou circular livremente, o sono era sua ocupação predileta. Mas havia em sua fala um desejo de sair desse ócio. As visitas domiciliares da terapeuta ocupacional fundamentaram a adesão da Joana ao projeto "Brincar e Contar", pois apesar de ela exprimir a demanda da fazer algo para sair do ócio, a ideia de ela ser o foco em qualquer intervenção era algo ameaçador, por isso a estratégia de propor açóes em que ela não fosse o centro da intervenção. Foi feito o convite para Joana participar da construção do projeto "Brincar e Contar", com as propostas de ela ser uma das coordenadoras e de que sua casa fosse o espaço em que se realizassem as atividades. A casa iria ganhar um novo sentido para ela e para a comunidade.

A Terapia Ocupacional vislumbrou as possibilidades de sua atuação na atenção básica: construir ações a partir dos potenciais que o território oferece tanto para se pensar o cuidado individual quanto o grupal e/ou coletivo. Assim, a análise do cotidiano e rotina tanto da Joana quanto das crianças e da equipe possibilitou a elaboração de uma atenção coletiva e individual em diálogo e com isso permitiu um processo de ressignificação do cotidiano de Joana, bem como da comunidade e equipe. Ao longo da vida e da história individual e/ou coletiva, atividades cotidianas variadas assumem papel preponderante, para serem mais tarde descartadas ou modificadas conforme alcançam o limite do tempo individual, o status de conquista coletiva ou de mudança sócio-histórica. A cotidianidade varia conforme o contexto, isto é, varia conforme a classe social, os laços culturais, o gênero, a idade (GALHEIGO, 2003). A análise da Terapia Ocupacional considerou a cotidianidade entrelaçada desse território em seus diversos aspectos, tanto relativos às pessoas que o compóem, quanto à formação dele mesmo, historicamente, e à classe social nele predominante, e esse olhar desenvolveu na prática a construção de uma abordagem em rede com o cuidado individual e coletivo de forma ampla.

Segundo Campos et al. (2008),

A abordagem ampliada depende da reformulação do paradigma tradicional denominado biomédico. Para isso, recomenda-se tomar o sujeito em sua família e em seu contexto econômico, social e cultural, bem como envolver os usuários tanto na gestão do sistema de saúde quanto na construção de sua própria saúde [...] (p. 142).

Por meio dessa proposta, novas atividades estavam implícitas no cotidiano da usuária, da equipe e da comunidade. Canguilhem (1978), apud Figueiredo e Furlan (2008, p. 163), fundamenta-se para justificar a importância e possibilidades de açóes fora do padrão biomédico: "[...] a saúde deve ser pensada como capacidade de instaurar novas normas diante de situações novas [...]". Saúde como uma capacidade criativa:

[...] um sentimento de segurança na vida [...] uma maneira de abordar a existência com uma sensação não apenas do possuidor ou portador mas também, se necessário, de criador de valor, de instaurador de normas vitais [...] (CANGUILHEM, 1978, apud FIGUEIREDO; FURLAN, 2008, p. 163).

Ou seja, uma concepção de saúde que pressupõe uma posição ativa do sujeito, uma potência para inventar estratégias de sobrevivência diante das condiçóes de seu contexto.

De acordo com Vasquez (1977), o fazer é uma atividade propriamente humana que só se verifica quando os atos são dirigidos a um objeto para transformá-lo, se iniciam com um resultado ideal ou finalidade e terminam com um resultado ou produto efetivo real. Já segundo Heller (2000), o cotidiano pode ser entendido como o lugar da repetição, do concreto, da experiência vivida. Constitui também um espaço de transformação, pois é nele que ocorrem relaçôes sociais e se articulam a produçáo e a reprodução; o banal e o importante; o privado e o público.

Diante das colocaçóes do fazer e do cotidiano, achou-se necessária a inserção da definição de Terapia Ocupacional elaborada pela Associação Americana de Terapia Ocupacional (AOTA): a análise e aplicação de ocupaçôes selecionadas do cotidiano que tenham um sentido ou um propósito para o indivíduo, permitindo ao mesmo ganhar, recuperar, aumentar ou prevenir a perda das habilidades ocupacionais, tarefas, rotinas ou papéis que ele tenha desempenhado no passado ou está aprendendo a desempenhar. Sendo assim, pode participar como um membro contribuidor o mais completo possível no seu meio social, pessoal e econômico (REED; SANDERSON, 1999). Nesse contexto, Joana aceitou participar do projeto. 


\section{Tecendo encontros}

Com essas demandas, a terapeuta ocupacional identificou a possibilidade de interrelacioná-las. São cotidianos que de certa forma mostravam uma falta de sentido nos seus fazeres. As crianças buscavam espaços para brincarem juntas, Joana buscava espaços de sentido e circulação e a terapeuta ocupacional, junto com a educadora física, coordenavam o propósito para a construção de uma brinquedoteca, desejo construído da equipe. Essa ideia de junção desses contextos foi levada para a equipe e posteriormente para Joana que, como já supracitado, participou da construção do projeto "Brincar e Contar" como uma das coordenadoras - sendo a educadora física e a terapeuta ocupacional as outras coordenadoras. Coordenar o projeto significou para Joana apreender novas funçôes: planejar atividades a serem realizadas, executar, avaliar e relatar os acontecimentos do dia através de um diário de campo. Introduzia também no cotidiano dela o trabalho em parceria. A dinâmica do projeto acontecia na garagem da casa de Joana e ela atuava também como contadora de histórias.

O projeto aconteceu entre janeiro de 2010 e fevereiro de 2011. Nesse processo, todos os profissionais da equipe matricial e de referência foram convidados a uma participaçáo pontual para se aproximarem da formaçáo da ideia e, posteriormente, uma agente comunitária passou a colaboradora efetiva. $\mathrm{O}$ atual formato do projeto com a inserção da equipe, incluindo um usuário do território e a comunidade, caminhou para o objetivo de construir uma brinquedoteca no bairro, pois o local não possuia nenhum dispositivo social de lazer que a população pudesse frequentar. $\mathrm{O}$ fato de o projeto ter se iniciado na casa de Joana despertou a comunidade para a questão e mobilizou a realizaçáo de um abaixo-assinado reinvidicando esse espaço.

Observa-se que há uma apropriação, pela usuária, pela equipe e pelas crianças, da prática da saúde coletiva, que tem por objetivo ampliar a capacidade de análise e intervenção dos sujeitos sobre a realidade em que estão inseridos (MASSUDA, 2008). Justifica-se assim a transformação na rotina de Joana, que passou a acordar cedo e a buscar recursos externos para viabilizar o projeto. Também houve a transformação da rotina das crianças, que têm um espaço qualificado de brincar uma vez na semana, e na equipe, que vivencia novos modos de fazer saúde: como, por exemplo, a agente comunitária - que náo se limita mais a apenas realizar visitas domiciliares - inserida no projeto e nas reflexóes sobre o tema que hoje a equipe faz.

Segundo Campos et al. (2008), uma das diretrizes para que a Atenção Básica à Saúde atinja essa capacidade de resolver problemas é a:

[...] reformulação do saber e da prática tradicional em saúde: recomenda-se uma reformulação e ampliação do saber clínico, com a incorporaçáo de conceitos e de ferramentas originários da saúde coletiva, saúde mental, ciências sociais e de outros campos do conhecimento que permitam aos trabalhadores de saúde lidar com a complexidade do processo saúde e doença, incorporando o social e o subjetivo, bem como fazer a gestão do trabalho em equipe e em sistemas de saúde (p. 141).

Acredita-se que a óptica da Terapia Ocupacional para as rotinas e cotidiano, juntamente com os pressupostos da saúde coletiva contribuíram para que essa vivência retratasse uma efetiva mudança de paradigma na prática em saúde nesse território. A transformação do modelo assistencial foi realizada na prática. O projeto "Brincar e Contar" corresponsabilizou os atores no território: usuários, comunidade e equipe de saúde - matricial e referência. O projeto gerou impactos positivos nos atores envolvidos: a equipe de saúde, as crianças e a usuária coordenadora, pela forma com que o mesmo foi estruturado.

No caminhar do projeto, Joana inseriu-se em lutas por melhoria das condiçôes de vida das crianças do bairro em que mora e da própria vida: retomou os tratamentos fisioterápicos e aderiu ao acompanhamento nutricional movida pelo desejo de voltar a andar e ampliar seu espaço social. Atualmente frequenta o grupo de artesanato da USF e se cadastrou no projeto ATO (Açáo, Trabalho e Oportunidade) da prefeitura municipal de São Carlos, que prevê a inclusão de pessoas portadoras de deficiência e reabilitadas no mercado de trabalho formal por meio de um processo de capacitação e acesso a vagas em empresas locais. As crianças ganharam um espaço de brincar, bem como puderam ser cuidadas de forma diferente pela equipe. Nesse espaço, vivenciaram regras importantes de serem apreendidas no coletivo, sentiram-se livres para refletir a respeito de dúvidas sobre o próprio corpo, sobre povos, culturas, deficiências, entre outros temas. Também foram identificadas pelas coordenadoras, através do brincar, algumas limitaçóes e dificuldades das crianças como: surdez, problemas de leitura e fala, todas encaminhadas a cuidados pertinentes. 
Os atores vivenciaram concretamente conceitos ampliados de saúde, portanto o processo foi potencializador da mudança de modelo de saúde biomédico para um modelo de saúde integral.

\section{Considerações finais}

Desde a conquista do SUS (Sistema Único de Saúde), a atenção à saúde vem se transformando e, principalmente, a organização da atenção básica. Ao longo dos últimos anos houve várias formas de organizar a atenção básica no Brasil. Desde 1994, com a criação do Programa Saúde da Família (PSF) pelo Ministério da Saúde, depois denominado Estratégia Saúde da Família (ESF), passou-se a incentivar financeiramente um modelo específico de organização de rede de atençáo básica que traz em seu escopo um conjunto de diretrizes, como o trabalho em equipe de base territorial, a promoção e a prevençáo da saúde, um perfil de profissional generalista, a incorporação do agente comunitário de saúde, a normatizaçáo do processo de trabalho, entre outras.

O processo de mudança dos paradigmas do cuidado em saúde através da implantação da ESF (Estratégia Saúde da Família) é indicativo de transformação do modelo de atenção. Porém, fazer essa mudança ocorrer na ação cotidiana dos profissionais de saúde que são formados em outros modelos de cuidado e no cotidiano da população é um trabalho árduo e que acontece na própria ação cotidiana. Segundo Campos et al. (2008):

[...] apesar da franca expansão da ESF em algumas regióes do país, é importante reconhecer que estamos longe de dispor de uma rede de atenção básica com ampla cobertura e com eficácia adequada [...] (p. 144).

Realizar o projeto "Brincar e Contar" abriu a possibilidade de fortalecer esse processo de mudança na saúde através de uma ação preventiva e curativa, pois se trata de um atendimento individual que compóe com uma ação coletiva para a comunidade, mostrando uma possibilidade de ampliação do cuidado individual para o coletivo, na perspectiva da mudança da lógica do cuidado em saúde, através do saber terapêutico ocupacional articulado com outros saberes e com os pressupostos da saúde coletiva.

A Terapia Ocupacional é uma profissão da área de saúde que tem interlocução com diversas áreas do saber, como a educação, o social, o saber popular, a arte, a cultura, entre outras. O objeto de estudo é o cotidiano, o fazer humano, por esse motivo é algo complexo no qual naturalmente há a profusão de saberes em sua atuação. A terapeuta ocupacional no contexto apresentado buscou ressignificar o cotidiano das pessoas em seu potencial, portanto foi possível articular neste projeto as potencialidades do indivíduo, do território, da equipe e do coletivo.

\section{Referências}

BARROS, D. D.; GHIRARDI, M. I. G.; LOPES, R. E. Terapia Ocupacional Social. Revista de Terapia Ocupacional da Universidade de São Paulo, São Paulo, v. 13, n. 3, p. 95-103, set./dez. 2002.

BETTELHEIM, B. Uma vida para seu filho. Rio de janeiro: Campus, 1998.

BRASIL. Presidência da República. Subchefia para Assuntos Jurídicos. Lei no 8.069, de 13 de julho de 1990. Dispóe sobre o Estatuto da Criança e do Adolescente e dá outras providências. Diário Oficial da República Federativa do Brasil, Brasília, DF, Poder Executivo, 16 jul. 1990. Seção 1. Disponível em: <http://www.planalto.gov.br/ ccivil_03/Leis/L8069.htm>. Acesso em: 15 jan. 2011.

BUNDY, A. C. Recreação e entretenimento: o que procurara. In: PARHAM, L. D.; FAZIO, L. S. A recreação na Terapia Ocupacional Pediátrica. São Paulo: Santos, 2000. p. 52-66.

CAMPOS, G. W. S. et al. Reflexôes sobre a Atenção Básica e a Estratégia Saúde da Família. In: CAMPOS, G. W. S.; GUERRERO, A. V. P. Manual de Práticas de Atenção Básica: Saúde Ampliada e Compartilhada. São Paulo: Hucitec, 2008. p. 132-53.

DEBORTOLI, J. A. O.; LINHALES, M. A.; VAGO, T. M. Da articulação entre a formação dos docentes de Educação Física e a formação dos profissionais de educação infantil para a ação - reflexão da prática. In: BORGES, C.; DESBIENS, J. F. (Orgs.). Saber, formar e intervir: para uma Educação Física em mudança. Campinas: Autores Associados, 2005. p. 191-211. (Coleção Educação Física e Esportes).

DIMENSTEIN, G. O mistério das bolinhas de gude: histórias de humanos quase invisíveis. Campinas: Papirus, 2006.

FIGUEIREDO, M. D.; FURLAN, P. G. O subjetivo e o socio-cultural na co-produção de saúde e autonomia. In: CAMPOS, G. W. S.; GUERRERO, A. V. P. Manual de Práticas de Atenção Básica: Saúde Ampliada e Compartilhada. São Paulo: Hucitec, 2008. cap. 6, p. 154-178

GALHEIGO, S. M. O cotidiano na terapia ocupacional: cultura, subjetividade e contexto histórico-social. Revista de Terapia Ocupacional da Universidade de São Paulo, São Paulo, v. 14, n. 3, p. 104-9, set./dez. 2003.

GALLETTI, M. C. et al. CECCO: Brincando no Território. 2008. 13 p. Um dos 200 premiados do Brasil pelo Ministério da Cultura no Prêmio de Ludicidade, Pontinhos de Cultura. Projeto não publicado.

HELLER, A. O cotidiano e a história. 6. ed. São Paulo: Paz e Terra, 2000. 
MASSUDA, A. Práticas de Saúde Coletiva na Atenção Primária em Saúde. In: CAMPOS, G. W. S.; GUERRERO, A. V. P. Manual de Práticas de Atenção Básica: Saúde Ampliada e Compartilhada. São Paulo: Hucitec, 2008. p. 179-205.

REED, K. I.; SANDERSON, S. N. Concepts of Occupational Therapy. Baltimore: Lippincott Williams \& WilKins, 1999.
WINNICOTT, D. W. A criança e seu mundo. Rio de Janeiro: Ed. Zahar, 1975a.

WINNICOTT, D. W. O brincar e a realidade. Rio de Janeiro: Imago, 1975b.

VASQUEZ, A. S. Filosofia da práxis. Rio de Janeiro: Paz \& Terra, 1977.

\section{Contribuição dos Autores}

Débora: Concepção do texto manuscrito, redação do texto, organização das referências bibliográficas. Cristiane: Revisão do texto, orientação sobre o manuscrito, redação do texto, organização de fontes e metodologia do texto.

\section{Notas}

${ }^{1}$ Esse relato faz parte da intervenção da Terapia Ocupacional no Programa de Residência Multiprofissional em Saúde da Família e Comunidade da UFSCar.

${ }^{2}$ Nome fictício, para resguardar a identidade da usuária.

${ }^{3}$ Bingão da Saúde - Tratam-se de rodas de conversa realizadas sobre temas previamente escolhido por integrantes do grupo, geralmente problemas cotidianos do bairro. A conversa é mediada por um membro da equipe de residentes da USF Romeu Tortorelli. As ideias e os pensamentos são anotados em um quadro, sendo destacadas suas palavras-chave. As pessoas recebem as cartelas de bingo em branco para inserir as palavras com as quais mais se identificam. Inicia-se então o jogo pelo sorteio das palavras-chave, com prendas doadas pela comunidade, comércio local ou equipe.

${ }^{4}$ Equipe matricial é composta por vários profissionais da área de saúde e objetiva assegurar retaguarda especializada a equipes de referência, que são encarregadas da atenção a problemas de saúde nos territórios. Oferece tanto retaguarda assistencial quanto suporte técnico pedagógico. 
